STUDI

FRANCESI

\section{Studi Francesi}

Rivista quadrimestrale fondata da Franco Simone

168 (LVI | III) | 2012

Varia

\title{
Tom Bruyer, Le Sang et les Larmes. Le suicide dans les tragédies profanes de Jean Racine
}

\section{Laura Rescia}

\section{(2) OpenEdition}

1 Journals

\section{Edizione digitale}

URL: http://journals.openedition.org/studifrancesi/3722

DOI: $10.4000 /$ studifrancesi.3722

ISSN: 2421-5856

\section{Editore}

Rosenberg \& Sellier

\section{Edizione cartacea}

Data di pubblicazione: 1 décembre 2012

Paginazione: 563

ISSN: 0039-2944

\section{Notizia bibliografica digitale}

Laura Rescia, «Tom Bruyer, Le Sang et les Larmes. Le suicide dans les tragédies profanes de Jean Racine»,

Studi Francesi [Online], 168 (LVI | III) | 2012, online dal 30 novembre 2015, consultato il 08 mars 2021.

URL: http://journals.openedition.org/studifrancesi/3722 ; DOI: https://doi.org/10.4000/studifrancesi. 3722

Questo documento è stato generato automaticamente il 8 mars 2021.

\section{(c) $(1) \ominus$}

Studi Francesi è distribuita con Licenza Creative Commons Attribuzione - Non commerciale - Non opere derivate 4.0 Internazionale. 


\title{
Tom Bruyer, Le Sang et les Larmes. Le suicide dans les tragédies profanes de Jean Racine
}

\author{
Laura Rescia
}

\section{NOTIZIA}

TOM BRUYER, Le Sang et les Larmes. Le suicide dans les tragédies profanes de Jean Racine, Amsterdam-New York, Rodopi, 2012, pp. 329.

1 È possibile individuare, nell'estetica della morte raciniana, uno specifico relativo alla figura del suicidio? E in che modo questo specifico tanatologico contribuisce alla configurazione poetica, drammaturgica ed estetica del tragico raciniano, nel dialogo tra testo e rappresentazione? Il complesso intendimento di Bruyer, attraverso un percorso chiaro e solidamente documentato (sono largamente utilizzate la critica italiana, tedesca e inglese oltre a quella francese) non giunge, per stessa ammissione dell'A., a risposte certe e univoche: le conclusioni (provvisorie) del saggio indicano ulteriori direzioni di ricerca, che potranno conseguire risultati più stringenti quanto meglio riusciranno a delimitare l'oggetto di studio, pur mantenendolo all'interno della problematica relativa all'estetica della violenza nel Grand Siècle.

Il primo capitolo è dedicato alla rilevazione della frequenza e della tipologia suicidaria in Racine (suicidio d'onore, d'amore, suicidio dei due amanti): ma lo studioso, per completare il quadro del corpus prescelto, è costretto a includervi anche il suicidio simbolico (rappresentato da Junie di Britannicus) e gli atti mancati (ovvero tutte le occorrenze dell'espressione di volontà di morte), forzando così, fin dall'inizio, il quadro metodologico prescelto. Nel secondo capitolo il suicidio viene considerato come cerimonia tragica, e l'evento inquadrato nel codice drammaturgico secentesco: la frequente presenza dell'altare, spazio preferito dell'azione, consente di suggerire un accostamento tra i rituali del matrimonio e della morte. È agli strumenti dell'atto 
anticonservativo che viene dedicato il terzo capitolo, in cui la simbologia del mezzo mortifero viene esaminata nel suo divenire storico: viene ripercorsa la lunga serie di varianti dei procedimenti utilizzati da Fedra, dalle fonti classiche a Racine. Qui l'A. dimostra una precisa conoscenza della trasmissione del mito, non trascurando di considerare l'importanza delle riscritture di La Pinelère, Gilbert et Bidard.

Constatata al termine della prima parte del saggio la prevalenza nelle tragedie raciniane del suicidio femminile, come apoteosi del parossismo amoroso, la presenza di uno spazio sacrale o parasacrale per l'azione suicidaria, e il ricorso maggioritario al veleno come mezzo, se ne apre una seconda, con il quarto capitolo dedicato alla teoria drammaturgica coeva. Viene messa in luce la parziale riabilitazione del suicidio d'onore, con una relativa riconciliazione della morale cristiana con l'etica classica, a partire dal Guarini e dai trattatisti italiani, per giungere, attraverso i teorici francesi della prima metà del secolo, agli anni Sessanta e al problema raciniano in senso stretto. Il quinto capitolo unifica, nella dialettica innovazione/imitazione, le letture di Iphigénie e Bajazet: poggiando sulla metodologia della génétique théâtrale presa a prestito dalla teorizzazione elaborata da Forestier, l'A. indaga la funzione drammaturgica del suicidio di Eriphile, inventato da Racine per riunificare le due letture del mito di Ifigenia, e utilizzato funzionalmente al dénouement della tragedia; per poi studiare la morte di Atalide, inventata e addirittura messa in scena, e non spiegabile attraverso la semplice condanna del despotismo orientale. Il sesto capitolo si concentra infine sul contrasto tra la prima tragedia profana di Racine, $L a$ Thébaïde, abbondante in suicidi atti a suscitare crainte et pitié, e Bérénice, in cui invece i tre protagonisti annunciano reiteratamente il proprio sacrificio senza che vi sia, da parte di alcuno, un passaggio all'atto, e dove la strategia discorsiva è utilizzata per agitare lo spettro della morte, riuscendo in tal modo ugualmente a suscitare il pathos dello spettatore, fine ultimo della tragedia classica.

4 Forte di una bella chiarezza espositiva, fondato su una gran messe di letture critiche, questo lavoro risente in alcuni passaggi di un'impostazione scolastica, non liberandosi dalla tendenza all'eccesso citazionale (soprattutto di bibliografia secondaria), che a tratti soffoca lo spunto interpretativo dell'autore. Assai apprezzabile appare l'ampiezza di letture sull'atto suicidario (dall'approccio antropologico a quello storico-filosofico) evocate nella premessa, ma poi non utilizzate nella seconda parte, che tuttavia riesce ad individuare una certa coerenza interpretativa. 